\title{
Analysis on the Causes of the Problems in Oral Chinese Teaching for Tibet Preparatory Students
}

\author{
Yanhua Liao \\ Nanchang Institute of Science \&Technology, Nanchang 330108, China
}

Keywords: Tibet preparatory students, oral Chinese teaching, problems, causes

\begin{abstract}
Oral language teaching occupies an important position in a language teaching system. It is difficult for Tibet preparatory students to communication in oral Chinese. At present, higher vocational colleges have little effect on oral Chinese teaching for the special group of non-native Chinese, which requires teachers to explore more feasible teaching strategy. [1] The paper takes Tibet preparatory students in Nanchang Institute of Science \&Technology as the research object, investigates and analysis the status of oral Chinese teaching.
\end{abstract}

The current oral Chinese teaching system mostly adopts the Audio-lingual method to teach. The Audio-lingual method develops oral Chinese ability by practicing sentence structure, advocates teachers to introduce knowledge and explain the text, advocates students to imitate, repeat and memorize. In this way, the students can understand the Chinese knowledge, but it is a boring mechanical operation, the teaching atmosphere is dull, can not stimulate learning enthusiasm of students.

In the process of research on oral Chinese teaching in Nanchang Institute of Science \&Technology, the researcher designs a questionnaire for the 120 Tibet preparatory students of 2016 grade preparatory classes. The questionnaire is mainly to understand the actual situation of students' oral Chinese learning and teachers' teaching in order to find out the problems in the traditional oral Chinese teaching. The main contents of the questionnaire include three aspects: the oral Chinese learning situation of Tibet preparatory students; the traditional teaching situation of oral Chinese course for Tibet preparatory students; the expectation of Tibet preparatory students in oral Chinese teaching.

Through the questionnaires, we can see that the problems in the traditional oral Chinese teaching are mainly from the teachers, students, teaching conditions, and so on. the researcher understands the problems in oral Chinese teaching through the questionnaires, as shown in the following table:

Table1 The problems of students' feedback on oral Chinese course (multiple choices)

\begin{tabular}{lcc}
\hline \multicolumn{1}{c}{ Problems } & number & proportion \\
\hline a large number of grammar & 54 & $45 \%$ \\
lack of equipment for oral Chinese course & 18 & $15 \%$ \\
hard to get guidance due to the large number of classes & 26 & $21.67 \%$ \\
students lack of enthusiasm & 78 & $65 \%$ \\
teaching methods are monotonous & 79 & $65.83 \%$ \\
other & 15 & $12.5 \%$ \\
\hline
\end{tabular}

The table shows $45 \%$ of the students think grammar is too much, almost the same proportion of the students think that "students lack of enthusiasm " and " teaching methods are monotonous " is the biggest problem, about $65 \%$.

In order to find out the problems in oral Chinese teaching, the researcher interviews three teachers of oral Chinese course. The interview mainly includes three aspects: the cognitions of teachers to Tibet preparatory students; the designs of oral Chinese teaching; the evaluations of Tibet preparatory students for oral Chinese teaching. 
The research through the questionnaires and interviews to oral Chinese teaching show the following problems: the traditional oral Chinese teaching is teacher-centered teaching. The teaching method makes students lack of learning motivation, learn passively, and feel anxious in learning second language. Teachers play a leading role in teaching, the root cause of the above problems is that the teachers' educational philosophy is backward, and lack the consciousness of innovation.

(1) The lack of teachers' innovative consciousness and the stereotype of teaching style reduce students' initiative.

Teachers' teaching enthusiasm is not high and teaching method is single. Students lack learning motivation, learning is passive. They are the outstanding problems in oral Chinese teaching for Tibet preparatory students. From the perspective of classroom teaching, the rigid teaching style of teachers reduces the students' initiative, it is essentially caused by the lack of teachers' innovative consciousness.

The teaching methods of oral Chinese course are single, the teachers mainly use the traditional teaching methods in the class. The teachers explain and the students practice syntax in the classroom. The teaching atmosphere is dull to stimulate students' learning motivation. the stylized teaching makes the students lose the freshness of oral Chinese course, but the innovative teaching makes the class more interesting, various teaching activities and teaching methods attract students' attention, stimulate the learning motivation, improve learning initiative. The students' interest and initiative in learning, are influenced by teachers' personality and teaching style. The stereotyped teaching methods make oral Chinese learning become dull as ditch water.

Constructivism emphasizes the initiative of learning, students are the main body of information processing and the active constructors of meaning, not the passive receivers of knowledge. Students receive the knowledge only by their own constructs, the teachers can not only impart knowledge from the outside by repeating the sentence patterns, but also guide the students to produce new knowledge from existing knowledge. [2] Language teaching should be a kind of creative activity, which is necessary to fully mobilize the students' thinking, reconstruct the language knowledge according to the existing experience and master the language skills. It requires teachers to innovate teaching methods, create conditions to stimulate students' curiosity and excitement, make students become the main body of learning. However, in the traditional oral Chinese teaching, the teaching method is single, the teachers lack the innovative consciousness, ignore the main body position of the students. Teachers blindly explain, students passively accept, and then do mechanical imitation, can not mobilize the initiative of learning.

Constructivism emphasizes the social and situational nature of learning, attaches importance to cooperative learning and advocates situational teaching. Constructivism holds that the students acquire knowledge through the construction of meaning by the cooperation and communication between people in a certain situation. Therefore, the teachers should innovate teaching organization form, create a situation similar to reality, and guide the students to solve the problems in real life through cooperation and inquiry. But in the traditional oral Chinese teaching, teachers do not consider the diversity of teaching organization form, lack innovative consciousness. They focus on explaining knowledge, can not design rich and interesting activities to mobilize the students' initiative.

(2) The teachers are backward in the educational philosophy, stressful communication environment increases the students' anxiety.

Tibet preparatory students dare not speak Chinese, afraid of making mistakes, anxiety of learning oral Chinese is too high. Although the learning anxiety is an individual emotional reaction, but fundamentally speaking, the teachers are backward in educational philosophy, without strengthening the main position of students, providing a relaxed and pleasant language environment. Tibet preparatory students are not high level of oral Chinese, and sometimes the expression is not accurate, not fluent, they are passive and nervous when express in Chinese. But in the traditional oral Chinese teaching, the teachers are backward in the educational philosophy, adhere to Herbart's "teacher-centered theory" and emphasized the authority of teachers. They focus on teachers to create language environment, take roll call at random, correct language errors promptly and strictly, 
increase students' learning anxiety.

The teacher make the students practice oral Chinese by Audio-lingual method, show examples and the students express as the main form. The students completely follow the teacher's instructions when practice, generally do not encourage students to create their own interaction. The students mainly imitate the example of expression, usually in individual practice. Then the teacher ask a few students to speak. The random roll call makes the students nervous, because the oral Chinese language level of Tibet preparatory students is not high, speak alone and passively is more likely to cause anxiety.

Constructivism believes that the teacher is a facilitator of meaning construction, not the inculcation of knowledge. It requires teacher to change from the authority role of knowledge in traditional teaching to the students' learning mentor and collaborator. In the constructivist teaching, the teacher should pay attention to the practice of oral Chinese in the students' initiative, not force students to practice passively. It can promote the expression of the individual under the positive influence of the group by the way of group cooperation. a learning environment out of the native language can make the Tibet preparatory students feel at a loss. If the teacher can provide a relaxed teaching environment, take the students as the center when arrange oral practice, to create a good environment for oral practice ,and a good environment meeting the requirements of teaching content, it will reduce the students' anxiety. And if the teacher can inspire students to discover the rules, correct or supplement their own understanding, it will reduce the students' anxiety too. [3]

The interviews with teachers show that teachers can have different requirements on the accuracy, fluency and appropriateness of oral expression. When a student's pronunciation or grammar is incorrect, the teacher will correct them immediately, because they think that the accuracy of pronunciation and grammar is a prerequisite for speaking Chinese well. Teachers also pay more attention to the fluency, when students speak too slowly, repeat language again and again, but still express difficultly, some teachers will guide students to end the expression quickly, then ask the other students. The appropriateness of language to different occasions, different objects through the appropriate language to achieve the purpose of expression, which is a higher stage of the requirements to learners, teachers generally don't emphasize too much. Teachers pay too much attention to the accuracy and fluency of expression, which is easy to cause anxiety.

Constructivism holds that knowledge is not an accurate representation of reality, and that the students' acceptances of knowledge can only be accomplished by their own constructions. The study of the students is not only the understanding of new knowledge, but also the analysis, examination and criticism of new knowledge. [4] Therefore, in the evaluation of the students' language expression, the teacher should judge the rationality of the knowledge with the students' own experience as the background, and should not overemphasize the accuracy. The world is an objective existence, but the understanding of the world is determined by the individual. Because of the difference of personal experience, social and cultural background, each person has different understanding of the world. Relative to the accuracy and appropriateness of language, the researcher thinks that the basic requirement of oral communication is to express the real intention of the communicator, the traditional oral Chinese teaching in the Audio-lingual method, the teachers tend to correct language errors strictly at once. The teachers pay too much attention to pronunciation and grammar, and corrected immediately, emphasize language fluency, or even interrupt the expression of students, is more prone to cause anxiety.

The improvement of oral Chinese is one of the most important standards to measure the efficiency of oral Chinese teaching, but the Tibet preparatory students need to improve their oral Chinese ability by a large number of communicative practice and repeated practice. Teachers should provide students with more communicative situations, provide a relaxed and pleasant teaching environment in order to mobilize the majority of students to participate in classroom communicative activities, improve the communicative desire of students, provide a large number of effective language output to promote the Tibet preparatory students to improve the level of oral Chinese. 


\section{References}

[1] W.H. He. Study on oral Chinese teaching in Tibet class [J]. literature and art, 2013, (11): 254

[2] Twelve key Normal University jointly write. Education Foundation [M]. Education Science Press, 2008:205-206

[3] B.H. Wang Bilingual education and bilingual teaching [M]. Shanghai: Shanghai Education Press, 2003:156-158

[4] J. Wang .Study on the application of task-based cooperative learning model in oral Chinese teaching in Thailand .Chongqing University [D].2014. 